\title{
Analysis of Current Situation and Prospect about New Building Materials

\author{
Jing $\mathrm{Wu}^{1}$ \\ ${ }^{1}$ Urban Construction Department, Hubei Engineering University, Xiaogan, China
}

Key words: construction materials; development; analysis

Abstract. In this paper, current situation of the development of new construction materials were summed up and analyzed, and the future development trend of new construction materials is analyzed in view of the current market demand of new construction materials.

\section{Introduction}

Construction industry is the pillar industry of national economy in our country, construction materials is the material basis of construction production activities, like architectural design, architectural structure, architectural construction and construction economy, all of them is an important part of construction engineering discipline.Breakthrough and innovation of many technical problems in building engineering often depends on the construction material, and the emergence of new building materials will promote the structural design and construction technology innovation. With the development of social productive forces and the progress of science and technology, the building material just beyond the limitation by brick, wood, stone, soil restrictions for thousands years, cement and steel has been used extend, reinforced concrete structure also appears. With the advent of lightweight and high strength material,the development of modern architecture and high-rise buildings is also promoted, always update the requirements to the construction materials, some of the special features of the material also came into being. This shows that building materials production and the development of science and technology, not only have important influence to the development of the construction industry, but also affect regional and national economic development.

\section{Current Situation of the Development of New Building Materials}

New wall materials includes many varieties, mainly including bricks, blocks, plates, such as clay hollow brick, mixed waste clay brick, clay bricks, building blocks, aerated concrete, lightweight sheet composite board.The development of China's new wall material development is fast, in 1987, the new wall material output is 18.45 billions standard brick, to 1997 increased to 184.988 billions standard brick,the proportion of new wall materials in the total amount of the wall materials increased from $4.58 \%$ to $25.2 \%$.

After nearly 20 years of development, in recent years, China has been able to develop its own production technology and equipment, Wall material industry in our country has begun to walk the road of development of many varieties, initially formed a board of wall material system, such as hollow concrete block, gypsum board, fiber cement sandwich panels, and other.But all kinds of new light board, composite board is still very small, less than $1 \%$ of the total wall material, which can represent the modern technology,compared with the developed countries, the main features are: low 
grade, small business scale, backward technology and equipment,bad supporting ability. One of the important reasons for the slow development of new wall materials is that the limitation strength of the solid clay is not enough, lack of specific measures to protect land resources, in order to destroy the land to make the cost of clay brick is very low, so that any new wall material in the price can not compete.

Since the reform and opening up, China's thermal insulation material has made considerable progress, has developed into a relatively complete variety, taking shape of the insulation materials production and technology system. China's thermal insulation material products have been from scratch, from single to diversification, quality from low to high, has formed mainly in the expanded perlite, mineral wool, glass wool, foam, refractory fiber, calcium silicate insulation products, such a varieties of relatively complete industry,technology, production and equipment level has been greatly improved. But the overall technology and equipment level is still relatively low, the application technology in the construction field also has to be improved, and the promotion of heat preservation materials is restricted to a large extent. In the other hand, insulation materials industry redundant construction phenomenon is serious, swarming all over the country, and the development in the field of application is not input, resulting in a current investment benefit is low, the oversupply situation. At present, the main problems of the heat preservation material in our country is that the market application rate is low, the overall level of production technology and management level is low, the product quality is not stable, scientific research investment is insufficient. In particular, the research and development of heat preservation material in the construction of the application technology has been slow, which seriously affected the healthy development of the insulation material industry. To strengthen the work of new type of heat preservation and heat insulation materials and thew other new building materials products design is the top priority in order to develop the new building materials industry.

At present, the three star hotel decoration materials can be supplied by domestic production, four star, five star hotel decorated with $30 \%$ to $40 \%$ can be achieved. The main problems of building decoration materials industry is that the production enterprise scale is small, the product quality is not stable, the color is old, the grade is low, the support is poor, the market competition ability is weak; lack of scientific research and development, product upgrading ability is weak, can not meet the needs of the market; unreasonable product structure, the proportion of middle and low grade products, the proportion of high-grade materials is low, can not meet the needs of high-grade construction decoration decoration.

With the continuous development of prestress technology and lightweight materials have appear, the developing direction of the bridge is the new, large span, light and beautiful, environmental protection, human nature. While every major technological developments of the bridge are close contact with material, technology of construction and the structure.

\section{Development Trend of New Building Materials}

So far, the life of ordinary buildings is generally set at 100 for 50 years. The construction of the infrastructure of modern society is becoming more and more large-scale, integrated, large-scale 
projects such as high-rise buildings, large water conservancy facilities, submarine tunnel, costing huge, long construction cycle, maintenance difficulties, so the durability requirements are higher. In addition, with the development of human beings on the ground, the ocean and other harsh environment, but also requires high durability of the materials. At present. The main objectives of the development is that high durability concrete, reinforced concrete, steel rust proof, ceramic outer wall of the tire surface material, pigment resin coating, moth proof material, resistance to low temperature materials, as well as in underground, marine, high temperature and other harsh environment can be preserved for a long time performance of the material. In the large space building, the fifth generation of the building membrane material is widely used new materials, it is by the polymer coating and the substrate according to the required thickness, width by a special processing technique adhesive. Now it can play a great bearing capacity, to build a flexible space, and has a natural ecological beauty. The depth of the underground space is a field has not been widely developed, with the area of the earth's land surface is decreasing year by year, human in addition to the development of high altitude, depth of the underground is a very potential space for development. Compared with high-rise buildings, underground space structures have many advantages. For example, with heat preservation, heat insulation, wind and other characteristics, energy consumption can be saved. In order to achieve the construction of large underground space, it is needed to develop new materials, such as pharmaceutical materials, biological materials, soil amendments, and water purification, which can meet the requirements of the underground environment.

The working environment of the marine construction and the land building is very different. In order to realize the use of the marine space, the materials of the marine construction must be developed. Salt, chloride ion, sulfate in the sea water, so that the material is easy to be corroded and destroyed. The sea waves different reciprocating action, and the impact of the building, wear and fatigue loads. Marine structures are often subjected to severe weather conditions such as typhoons, tsunamis, and so on. Building on the beach, offshore and other soft foundation on the building, the phenomenon of its settlement is also very obvious. These materials which is used in harsh environment of marine structures, requirements with very high strength, impact resistance, fatigue resistance, abrasion resistance and mechanical properties, is also required to have excellent corrosion resistance. To achieve these properties, the following new materials are required to be developed, such as coating metal plate, corrosion resistant metal, cement matrix composite reinforced material, foundation strengthening materials, etc. In order to achieve the goal of sustainable development to control the load of building materials to the environment within the minimum, to develop environmental protection building materials is needed. Such as the use of industrial waste can produce cement, block and other materials: use the waste plastics produce heat preservation wall panels. Use the waste glass produce laminate materials, etc.. Can reduce the solid waste of the stock, reduce environmental pollution, but also save the natural material, has a positive effect on the protection of the environment and the protection of the earth. Unburned ement can save the energy in the consumption of cement production.High flow pattern, self compacting and free vibration of concrete, can not only save energy, but also can reduce the noise. 
Building materials also have a tendency to develop further, along with the development of nano technology and nano materials, the building materials that foreign and domestic use by nano materials to research and application mainly is nano titanium dioxide photocatalytic eco building materials. Including air purification building materials, antibacterial sterilization building materials, deodorant and surface cleaning materials, etc..

With the development of human intelligence, intelligent material is also being valued and developed. The so-called intelligent material, that is, the material itself has a self diagnosis and prediction of damage, self adjustment and self repair function, and can be reused. Such materials can reflect the internal conditions of the material when here has some unknowed change, such as displacement, deformation, cracking and so on. In order to take effective measures before the destruction; at the same time, the intelligent material can self adjust according to the bearing capacity and the external function, such as moisture absorption and desorption material, according to the humidity of the environment automatically absorb or release water, can maintain the environment and humidity balance; automatic dimming glass, according to the external light intensity, adjust the light, to meet the requirements of indoor lighting and health. Intelligent material also has the function of self growth and metabolism, which is similar to the biological, and self repair of the damaged or damaged parts. When buildings collapse, the material itself can also be used to reduce construction waste. The research and development of this kind of material is in the initial stage, and the function of self diagnosis, forecast and self adjustment has been made.

Eco building materials are also in the study, the concept of eco building materials from the ecological environment materials. The main characteristics of ecological environment material is to save resources and energy; reduce environmental pollution, avoid the greenhouse effect and ozone layer; easy recovery and recycling. As an important branch of ecological environment, according to the meaning of ecological building materials, ecological building materials should refer to the process of production, use, waste and recycling should be coordinated with the ecological environment, and which meet the minimum of resources and energy consumption, minimum or no environmental pollution, the best use of performance, the highest recycling rate.

\section{References}

[1] Jin Lei, Architectural science and culture (1999)

[2] Yang Jing, Building materials and human settlement (2002)

[3] Luo Deqi, Construction of healthy human settlement, Journal of Architecture 4 (2004) 35-38. 